\title{
Expression of cytochrome P450 2C9 (CYP2C9) in Escherichia coli and its functional characterization
}

\author{
Boon Hooi Tan', Yan Pan ${ }^{\mathrm{b}}$, Uma Devi Palanisamyc, Iekhsan Othman ${ }^{\mathrm{c}}$, Nafees Ahmed ${ }^{\mathrm{d}}$, Beow Chin \\ Yiap ${ }^{\mathrm{e}}$, Chin Eng Ong ${ }^{\mathrm{e}^{*}}$ \\ aDivision of Applied Biomedical Science and Biotechnology, School of Health Sciences, International Medical University, Jalan Jalil Perkasa 19, \\ Bukit Jalil, 57000 Kuala Lumpur, Malaysia \\ ${ }^{b}$ Department of Biomedical Science, The University of Nottingham Malaysia Campus, Jalan Broga, 43500 Semenyih, Selangor, Malaysia \\ Jeffrey Cheah School of Medicine and Health Sciences, Monash University Malaysia, Jalan Lagoon Selatan, 47500 Bandar Sunway, Selangor, \\ Malaysia \\ 'School of Pharmacy, Monash University Malaysia, Jalan Lagoon Selatan, 47500 Bandar Sunway, Selangor, Malaysia \\ eschool of Pharmacy, International Medical University, Jalan Jalil Perkasa 19, Bukit Jalil, 57000 Kuala Lumpur, Malaysia
}

Received 23rd September 2016 / Accepted 9th December 2018

\begin{abstract}
This study aimed to express the major human hepatic drug metabolizing cytochrome P450 (CYP), CYP2C9, together with NADPH cytochrome P450 oxidoreductase (OxR) in Escherichia coli and to evaluate its catalytic activities. Co-expression of CYP2C9 and OxR was achieved by means of separate, compatible plasmids with different antibiotic selection markers. The expressed proteins were evaluated by immunoblotting and reduced CO difference spectral scanning. Enzyme activities were examined using high performance liquid chromatography (HPLC) assays with probe substrates valsartan and tolbutamide. Results from immunoblotting demonstrated the presence of CYP2C9 protein in bacterial membranes and reduced CO difference spectra of the cell preparations exhibited the characteristic absorbance peak at 450 $\mathrm{nm}$. Co-expressed OxR also demonstrated an activity level comparable to previously published data. Kinetic parameters, $\mathrm{K}_{\mathrm{m}}$ and $\mathrm{V}_{\max }$ values determined from the valsartan and tolbutamide hydroxylase assays, were also concordant with literature values. As a conclusion, the procedures described in this study provide a relatively convenient and reliable means of producing catalytically active CYP2C9 suitable for drug metabolism and interaction studies.
\end{abstract}

Keywords: Cytochrome P450, Escherichia coli, heterologous expression, human CYP2C9, kinetic analysis

\section{INTRODUCTION}

Cytochromes P450 (CYPs) constitute a large family of heme-containing enzymes, all of which catalyse the oxidation of a variety of endogenous and exogenous compounds, including drugs, carcinogens, and other xenobiotic chemicals. Knowledge regarding CYPs is therefore crucial to the fields of drug therapy and drug development, as well as in our understanding of the mechanisms underlying the metabolic activation of potentially toxic and carcinogenic compounds.
CYP2C9 is one of the major enzymes that constitutes approximately $20 \%$ of total human liver microsomal CYP proteins and metabolizes approximately $15-20 \%$ of therapeutically important drugs that undergo phase I metabolism, including anticoagulants (warfarin), hypoglycaemic agents (tolbutamide and glimepiride), non-steroidal anti-inflammatory drugs (flurbiprofen and diclofenac), diuretics (torsemide), antihypertensives (losartan and

\footnotetext{
* Author for correspondence: Prof. Chin Eng Ong, School of Pharmacy, International Medical University, Jalan Jalil Perkasa 19, Bukit Jalil, 57000 Kuala Lumpur, Malaysia. Email - ceong98@hotmail.com
} 
valsartan), and anticonvulsants (phenytoin) (van Booven et al., 2009). As with many other CYP isoforms, CYP2C9 has been the main focus of many in vitro studies. However, conventional in vitro studies for human CYPs using human liver microsomes, liver homogenates or hepatocyte culture are facing several constraints and challenges such as limited tissue source, ethical clearance issue and concerns as well as intricate isolation and long-term storage procedures (Ong et al., 2013). As a solution to these problems, heterologous expressions of the human CYPs are made available in various host cells, including yeast, mammalian, insect, and bacterial cells. These systems have now become a routine and reliable resources for conducting drug metabolism and interaction investigations. Their use provides an effective way to further confirm results obtained from metabolism studies using microsomes or other tissue sources. Moreover, the activity of one specific human CYP can be studied in isolation. Recombinant preparations may also prove useful in cases where the enzyme in question may not be present in sufficient quantity in liver tissues. Also, due to the fact that only a single CYP enzyme is present, the need for a highly selective substrate probe is not required. These enzyme preparations generally afford a high level of reproducibility - once the expression plasmids are constructed and maintained in host cells, and the expression protocols are optimized, the cDNA clones represent a virtually inexhaustible supply of the proteins for routine use in the laboratories (Foti et al., 2010).

The present study describes the expression of recombinant CYP2C9 in E. coli together with its coenzyme NADPH cytochrome P450 oxidoreductase (OxR), as well as its functional characterization in reduced $\mathrm{CO}$ difference spectroscopy and high performance liquid chromatography(HPLC)-based assays using valsartan and tolbutamide as the probes. Although CYP2C9 has been expressed in different expression systems and characterized using a number of substrate probes, little is known regarding the kinetic behaviour of the bacterial expressed CYP2C9 in hydroxylation of valsartan. In this paper, the expression of CYP2C9 in E. coli and its kinetic characterization of valsartan oxidation, together with that of tolbutamide, are described.

\section{MATERIALS AND METHODS}

Materials and chemicals. Luria-Bertani (LB) broth was purchased from Conda Pronadisa (Spain). Chloramphenicol and ampicillin were purchased from Nacalai Tesque (Japan). Terrific broth (TB), sucrose, Tris, glycine, sodium chloride $(\mathrm{NaCl})$, sodium dodecyl sulfate (SDS), isopropyl $\beta$-D-1-thiogalactopyranoside (IPTG), $\delta$ aminolevulinic acid ( $\delta$-ALA), ethylenediaminetetraacetic acid (EDTA), phenylmethanesulfonyl fluoride (PMSF), glucose6-phosphate (G6P), glucose-6-phosphate dehydrogenase (G6PD), $\beta$-nicotinamide adenine dinucleotide phosphate reduced tetrasodium salt (NADPH), protease inhibitor, cytochrome c, magnesium chloride $\left(\mathrm{MgCl}_{2}\right)$, Bradford reagent, potassium phosphate monobasic and dibasic, sodium dithionite, glycerol, bovine serum albumin (BSA), valsartan, tolbutamide, and 4hydroxytolbutamide were purchased from Sigma (USA). 4'-Hydroxyvalsartan (mixture of diastereomers) was acquired from Santa-Cruz Biotechnology (USA). Dithiothreitol (DTT) was purchased from Promega (USA). Potassium cyanide $(\mathrm{KCN})$ and methanol were purchased from Fisher Scientific (USA). Precast polyacrylamide gels, Laemmli sample buffer and prestained sodium dodecyl sulfate-polyacrylamide gel electrophoresis (SDS-PAGE) low range standards were products of Bio-Rad Laboratories (USA). Western Max horseradish peroxidase (HRP) chromogenic detection kit was purchased from Amresco (USA). The cDNAs of CYP2C9 and the OxR were gifts from Professors John Miners and Donald Birkett (Flinders University, Adelaide, Australia). The CYP2C9 cDNA was provided as an insert in pCWorit expression vector while $\mathrm{OxR}$ cDNA was in $\mathrm{PACYC}$ vector.

Expression of recombinant CYP2C9 in E. coli. The expression of CYP2C9 and OxR was carried out following an established method (Gillam et al., 1994). The glycerol stocks containing the $\mathrm{pCW}-\mathrm{CYP} 2 \mathrm{C}$ co-transformed with pACYC-OxR into E. coli $\mathrm{DH} 5 \alpha$ competent cells, were revived by culturing overnight in LB media supplemented with $70 \mu \mathrm{g} \quad \mathrm{ml}^{-1}$ 
chloramphenicol and $50 \mu \mathrm{g} \mathrm{ml} l^{-1}$ ampicillin at $37^{\circ} \mathrm{C}$ under aerobic condition. The next day, each overnight culture was used to inoculate $350 \mathrm{ml}$ TB supplemented with the same concentration of chloramphenicol and ampicilin as in LB media and continued with incubation at $37^{\circ} \mathrm{C}$ in a shaking incubator. When the growth of the bacterial culture reached about 0.7 optical density at $600 \mathrm{~nm}$ wavelength, $1 \mathrm{mM}$ IPTG and $0.5 \mathrm{mM}$ $\delta$-ALA were added into the culture to induce the expression of the CYPs. The CYP expressions were continued at $30^{\circ} \mathrm{C}$ for 24 hours at a shaking speed of $200 \mathrm{rpm}$. The growth of the 24-hour incubated culture was arrested by chilling on ice for $10 \mathrm{~min}$. After that, the culture was harvested by centrifuging at $4^{\circ} \mathrm{C}$ for $10 \mathrm{~min}$ at the speed of $5,000 \mathrm{~g}$. The pellet was weighed before resuspended in Tris-EDTA-sucrose (TES). Freshly prepared lysozyme was added into the suspension and mixed gently, then the suspension was diluted one-fold with chilled distilled water $\left(\mathrm{dH}_{2} \mathrm{O}\right)$, followed by incubation on ice for $30 \mathrm{~min}$ with gentle shaking. After incubation, the mixture was centrifuged at $10,000 \mathrm{~g}$ for $10 \mathrm{~min}$ at $4^{\circ} \mathrm{C}$ to collect the spheroplast, which was then resuspended in spheroplasts resuspension buffer (SRB). PMSF (1 mM) and protease inhibitor $(1 \mathrm{ml}$ per $4 \mathrm{~g}$ wet cell) were added into the SRB suspension prior to sonication. After that, the bacterial lysate was centrifuged at 10,000 $\mathrm{g}$ for 20 min at $4^{\circ} \mathrm{C}$. The supernatant was removed carefully and subject to ultra-centrifugation at $180,000 \mathrm{~g}$ for $75 \mathrm{~min}$ at $4^{\circ} \mathrm{C}$ to collect the membrane fractions. The membrane fraction containing the CYP and $\mathrm{OxR}$ proteins were resuspended in TES-water in a ratio of 50/50 and stored at $-80^{\circ} \mathrm{C}$ until further use. The protein concentration for the recombinant protein was determined according to the Bradford's method (Bradford, 1976) using bovine serum albumin at different concentrations as the standard.

SDS-PAGE and Western blotting analysis. Prior to SDS-PAGE, the protein samples were treated with equal volume of sample buffer. The protein samples were then denatured at $95^{\circ} \mathrm{C}$ for 5 min using a heat block. After that, separation of the protein in the sample by size was conducted on Mini-PROTEAN® Tetra Cell (Bio-Rad Laboratories, USA), using 10\% MiniPROTEAN $^{\circledR}$ TGX $^{\mathrm{TM}}$ precast gels according to the protocols of Laemmli (Laemmli, 1970). By using micropipettor, $15 \mu \mathrm{l}$ of samples were gently loaded into each well. Electrophoresis was carried out at $100 \mathrm{~V}$ for $75 \mathrm{~min}$ or until the blue dye front has reached the bottom of the polyacrylamide gel. The separated protein from the polyacrylamide gel was transferred onto nitrocellulose membrane $(0.45 \mu \mathrm{m})$ through Western blotting using a semidry blotting system (C.B.S. Scientific Company, CA). The nitrocellulose membrane was presoaked in distilled water for $5 \mathrm{~min}$ and then briefly soaked in transfer buffer. The blotting was driven by at $5 \mathrm{~V}$ for $65 \mathrm{~min}$ under a constant current. Detection of the blotted CYP and OxR was carried out by using Western MAX HRP chromogenic kit (Amresco, USA). The nitrocellulose membrane was first rinsed in distilled water for $5 \mathrm{~min}$, followed by wash buffer for another $5 \mathrm{~min}$ on a rotary shaker. The membrane was then put into blocking buffer and incubated for one hour at room temperature on a rotary shaker. After that, the blocking buffer was discarded and the membrane was probed with primary antibody solution for one hour at room temperature. The primary antibodies used were rabbit anti-human cytochrome P450 2C9 polyclonal antibody (Millipore, USA), and anticytochrome $\mathrm{P} 450$ reductase, rabbit monoclonal antibody (Abcam, UK), both incubated at 1:10000 dilution. The primary antibody was then aspirated and the blot was washed with an ample amount of wash buffer for 5 min with agitation. The wash buffer was then discarded and this washing step was repeated twice. The membrane was transferred into secondary antibody solution containing HRP conjugated goat anti-rabbit IgG secondary antibody (Amresco, USA) and incubated for $30 \mathrm{~min}$ with gentle agitation at 1:10000 dilution. The secondary antibody was then discarded and the membrane was washed for three times with wash buffer, each for $5 \mathrm{~min}$. After washing, the membrane was then put into substrate solution containing 3,3'diaminobenzidine (DAB) substrate and incubated at room temperature until brown colour bands were seen on the membrane. The residual substrates were washed away by putting the membrane in distilled water for $5 \mathrm{~min}$ with agitation. Finally, the membrane was air-dried and stored in the dark. 
Spectral determination of $\boldsymbol{C Y P}$ content. The CYP content of the membrane fraction, which was indicator for holoenzyme level of the expressed protein, was determined spectrophotometrically by reduced-carbon monoxide (CO) difference spectroscopy (Omura and Sato, 1964). Firstly, the cell lysate was solubilized in $50 \mathrm{mM}$ phosphate buffer, $\mathrm{pH} 7.4$ containing $20 \%$ glycerol and then further diluted to $1 \mathrm{mg} \mathrm{ml}^{-1}$ with phosphate buffer. This protein sample was distributed equally into two quartz cuvettes with $1 \mathrm{~cm}$ path length. A pinch of solid sodium dithionite was added into each cuvette containing the sample and mixed well. The baseline between 400 and 500 was recorded using a double beam Shimadzu UV-1800 UV-VIS spectrophotometer (Shimadzu Corp., Japan). After that, $\mathrm{CO}$ was bubbled through the sample for $1 \mathrm{~min}$ and the spectrum was recorded. The concentration of CYP in the cuvette was calculated using Beer's Law equation (Equation 1):

$$
A=\mathcal{E} . \boldsymbol{c} . \boldsymbol{L}(\text { Equation 1) }
$$

where $\mathrm{A}$ was the difference in light absorption at $450 \mathrm{~nm}$ relative to $490 \mathrm{~nm}$, L was the light path of the cuvette and the extinction coefficient $\boldsymbol{E}_{450-490}$ was $91 \mathrm{mM}^{-1} \mathrm{~cm}^{-1}$.

\section{Determination of NADPH cytochrome P450 oxidoreductase activity. The activity of the co-}

expressed OxR was determined by NADPH cytochrome $\mathrm{c}$ reductase assay. This assay measures the reduction of cytochrome $\mathrm{c}$ by the OxR in the presence of NADPH (Vermilion and Coon, 1978). A dual-beam recording spectrophotometer (Jasco V-630) was set to time scan at a wavelength of $550 \mathrm{~nm}$. Two quartz cuvettes with $1 \mathrm{~cm}$ path length were prepared of which one served as reference cuvette and the other as sample cuvette. Each of the cuvette was filled with $1 \mathrm{ml}$ of cytochrome c solution $(0.125$ $\mathrm{mM}$ in $0.3 \mathrm{M}$ potassium phosphate buffer, pH7.7). After that, $200 \mu \mathrm{l}$ of $15 \mathrm{mM} \mathrm{KCN}$ was added into each cuvette. A measured amount of sample protein (final protein concentration of 0.5 $-1.0 \mathrm{mg} \mathrm{ml}^{-1}$ ) was added into each cuvette and mixed by gentle inversion. The baseline absorbance versus time at $550 \mathrm{~nm}$ was recorded for $2 \mathrm{~min}$. After that, a volume of $100 \mu \mathrm{lNADPH}$ solution was added into the sample cuvette and mixed gently by inversion. The increase in absorbance with time at $550 \mathrm{~nm}$ was recorded over $2 \mathrm{~min}$. The activity of reductase was determined by Equation 2, where 0.021 is the extinction coefficient for reduced cytochrome c and 1.2 is the total volume of reaction mixture in cuvette. The specific content of reductase (nmol cytochrome c reduced $\min ^{-1} \mathrm{mg}$ protein ${ }^{-1}$ ) was then calculated based on the concentration of protein in the sample.

$$
\text { Activity of cytochrome c reductase } \left.(\mathrm{nmol})=\frac{\Delta \mathrm{Abs} \text { at } 550 \mathrm{~nm} \mathrm{~min}^{-1}}{0.021} \times 1.2 \text { (Equation } 2\right)
$$

\section{Establishment of valsartan 4-hydroxylase} assay. The HPLC-based assay was established based on the published procedure (Nakashima et al., 2005) with some modifications. In this assay, valsartan was used as the substrate probe to investigate the catalytic activity of CYP2C9. In the presence of active CYP2C9, valsartan was converted into the 4-hydroxyvaleryl metabolite of valsartan (4-OH valsartan) through 4hydroxylation. In order to prepare the HPLC injection sample, an incubation mixture with total volume of $200 \mu \mathrm{l}$ was prepared in a $1.5 \mathrm{~mL}$ microcentrifuge tube. The stock solutions (10-50 $\mathrm{mM}$ ) for the substrate, valsartan, was prepared by dissolving the measured solid valsartan in $70 \%$ ethanol. The incubation mixture contained $0.1 \mathrm{mg}$ bacterial membrane protein, valsartan and
NADPH generating system (1 mM NADP, 10 $\mathrm{mM}$ G6P, 2 IU G6PD and $5 \mathrm{mM} \mathrm{MgCl}$ ) in $0.1 \mathrm{M}$ phosphate buffer at a $\mathrm{pH}$ 7.4. After that, the mixture was incubated at $37^{\circ} \mathrm{C}$ for $30 \mathrm{~min}$ in a water bath with gentle shaking. The reaction was terminated by adding $1 \mathrm{ml}$ of ice-cold acetonitrile with vortex mixing. After centrifugation at $1800 \mathrm{~g}$ for $5 \mathrm{~min}$ at $25^{\circ} \mathrm{C}$, the supernatant was carefully transferred into another tube and evaporated to dryness using a centrifugal evaporator with vacuum pump (Eyela, USA). The residue was dissolved in $200 \mu \mathrm{L}$ of $10 \%$ methanol with vortex mixing. After centrifugation at $1800 \mathrm{~g}$ for $5 \mathrm{~min}$ at $25^{\circ} \mathrm{C}$, an aliquot of $100 \mu \mathrm{l}$ was injected onto HPLC to determine the amount of $4-\mathrm{OH}$ valsartan formed in the catalytic reaction by CYP2C9. The analytical HPLC was carried out 
using Ascentis C18 column, $5 \mu \mathrm{m}$ with $150 \mathrm{~mm} x$ $4.6 \mathrm{~mm}$ I.D. (Supelco, USA), on the Agilent 1200 series HPLC systems and modules comprising vacuum degasser, quaternary pump, autosampler, fluorescence detector, and thermostatted column compartment (Agilent Technologies, Germany). The fluorescence detector was operated at excitation and emission wavelengths of $265 \mathrm{~nm}$ and $378 \mathrm{~nm}$, respectively. Elution of the injected sample was done by using mobile phase containing distilled water, acetonitrile, trifluoroacetic acid in the ratio of 55:45:0.1 at a flow rate of $1 \mathrm{ml} \mathrm{min}{ }^{-1}$. This mobile phase was filtered through a $0.45 \mu \mathrm{m} \times 47 \mathrm{~mm}$ nylon membrane and sonicated for $10 \mathrm{~min}$ prior to use. Agilent Chemstation for liquid chromatography Chem32 (Agilent Technologies, Germany) was used as the instrument control software for control and data evaluation. Overall assay withinday imprecision, assessed by measuring $\mathrm{OH}-$ valsartan concentrations in 3 separate incubations each was $5.9 \%, 3.6 \%$ and $1.3 \%$ for concentrations of $0.005 \mu \mathrm{M}, 0.05 \mu \mathrm{M}$ and $0.5 \mu \mathrm{M}$, respectively. Assay inter-day imprecision was determined to be $3.1 \%, 3.5 \%$ and $2.1 \%$ at the same concentrations as above.

\section{Enzyme kinetic characterization of CYP2C9.} Catalytic activity of the CYP2C9 was examined by incubating a series of concentrations (ranging from 10-1000 $\mu \mathrm{M}$ ) of valsartan with $0.1 \mathrm{mg}$ CYP2C9 in the reaction mixtures at $37^{\circ} \mathrm{C}$ for 30 min. Using these data, saturation plot was generated using EZ-Fit kinetic software (Perrella Scientific Inc, USA) to determine MichaelisMenten constant $\left(\mathrm{K}_{\mathrm{m}}\right)$ and maximum velocity $\left(V_{\max }\right)$ value. Saturation plot or substrate saturation curve is used to examine the change in reaction velocity as the substrate concentration is increased. The rate of reaction when the enzyme is saturated with substrate is designated as $V_{\max }$, whereas $K_{m}$ is expressed as half of $V_{\max }$. In addition to valsartan, the expressed CYP2C9 in this study was also examined for its kinetics using tolbutamide 4-methylhydroxylase assay. The details of this HPLC-based assay has been described in our earlier published papers (Pan et al., 2010; Pan et al., 2012).

\section{RESULTS}

Western blotting of CYP2C9 and $O_{x} R$ proteins. Expression of the recombinant CYP and OxR was carried out in E. coli and the extraction procedures released the expressed proteins from the harvested cell in the form of semi-purified membrane fractions. Membrane fractions extracted from E. coli cells harbouring the pCWorit plasmid without any gene inserts and expressed under the same conditions as the recombinant CYP and OxR served as control protein in this study. Separation of the protein mixtures in the membrane fractions by size was conducted using SDS-PAGE. The separated proteins were then transferred onto nitrocellulose membrane by semi-dry blotting and the target proteins were detected by matched antibodies as described under Materials and Methods. Colorimetric DAB substrates were used to detect the HRP-labelled target proteins and produced brown colour bands directly on the surface of the blots within seconds.

The results from immunoblottings showed the presence of immunoreactive band with molecular mass approximately $56 \mathrm{kDa}$ in the lane loaded with CYP2C9 (Figure 1a). The detected brown-coloured band indicated molecular mass corresponding to the reported molecular mass of this CYP isoform. There were no bands detected from the control protein at the same molecular mass, indicating the absence of CYP and thus confirmed the expression of immunoreactive CYP2C9 from the recombinant stocks. The presence of an extra band with higher molecular mass in CYP2C9 (Figure 1a) might be caused by non-specific binding of polyclonal primary antibody that was used in the immunoblotting. Immunoblotting was also carried out to detect the co-expressed OxR in E. coli. As shown in Figure $1 \mathrm{~b}$, a single protein band was detected with a molecular mass around $75 \mathrm{kDa}$ that was in accordance to the published molecular mass for OxR. Therefore, the expression of $\mathrm{OxR}$ in the fraction was confirmed. 


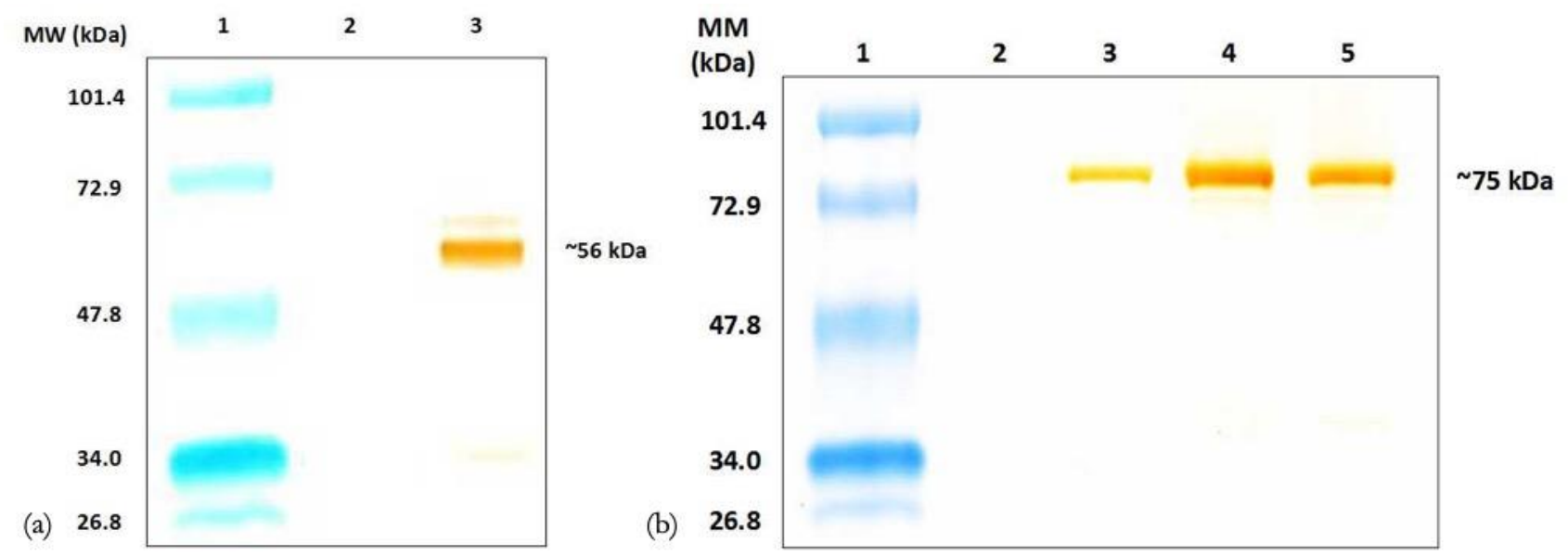

Figure 1. Western blot analysis on the expression of CYP2C9 (a) and OxR (b) in E. coli. SDS-PAGE were performed on $10 \%$ denatured polyacrylamide gels and the separated proteins were transferred onto nitrocellulose membranes. Immunodetection of CYP2C9 and OxR was done by using appropriate primary antibodies. Lane 1: Prestained protein standards, low range (Bio-Rad, USA); lane 2: membrane fractions extracted from control cell $(10 \mu \mathrm{g})$; lane 3: membrane fractions $(10 \mu \mathrm{g})$ containing the expressed CYP2C9 (a) and $\mathrm{OxR}$ (b). Lanes 4 and 5 in (b) are membrane fractions containing the expressed OxR derived from different stocks.

\section{Functional characterization of expressed} CYP2C9 and $\boldsymbol{O x}$. The membrane fractions prepared from the harvested E. coli cultures contained semi-purified CYP2C9 and OxR. Western blotting can only detect the presence of immunoreactive CYP2C9 in each membrane protein sample but not the specific CYP content. In order to quantify the actual CYP content in each membrane sample, reduced CO difference spectral assay was performed. The principle of this assay is that the reduced form of CYP (ferrous CYP) reacts with CO to form a complex that produces a distinguished Soret band at around $450 \mathrm{~nm}$, due to the signature cysteine thiolate axial ligand to heme iron in the CYP. The presence of Soret band around $450 \mathrm{~nm}$ in CYP2C9 protein sample (Figure 2) confirmed the expression of the active CYP. This assay was also used to characterize the recombinant CYP preparations in the context of stoichiometry of active CYP per unit protein. Using Equation 1, the spectral content of CYP2C9 was determined to be $366.0 \pm 16.8 \mathrm{pmol} \mathrm{mg}^{-1}$ protein. A relatively small absorbance peak was observed around 420 $\mathrm{nm}$ for CYP2C9 (Figure 2) due to low level of inactive CYP protein in the preparation. This level of inactive protein was however relatively small compared to the large absorbance peak of $450 \mathrm{~nm}$ which represented the active form.

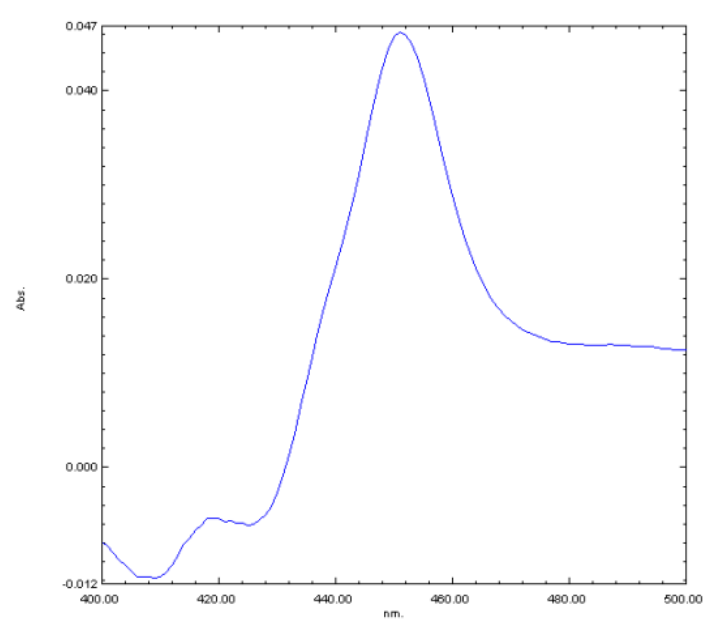

Figure 2. Carbon monoxide reduced spectrum used for the quantification of CYP content in the E. coli membrane protein preparation of CYP2C9. The reduced form of CYP bound to $\mathrm{CO}$ and produced a characteristic spectrum with a wavelength maximum at $450 \mathrm{~nm}$. The $x$ axis represents the wavelength $(\mathrm{nm})$ while axis y shows the absorbance of the CYP protein. The difference in absorbance unit was used to measure the spectral content of CYP in the tested protein samples.

On the other hand, the expression of spectrally active $\mathrm{OxR}$ in protein preparations was confirmed through the NADPH CYP oxidoreductase assay (Figure 3) and the level of 
expression was quantified using Equation 2. In this assay, OxR accepted electrons from the biological hydride donor NADPH and transferred these to cytochrome $\mathrm{c}$, therefore the activity of OxR was expressed as the molarity of cytochrome $\mathrm{c}$ reduced per $\mathrm{min}$ in one $\mathrm{mg}$ of protein sample. The rate of reduction of cytochrome $\mathrm{c}$ was measured from the absorbance difference at $550 \mathrm{~nm}$ wavelength per min from the spectrum recorded with spectrophotometer (Figure 3). From the results, the cytochrome c reduction activity per $\mathrm{mg}$ protein preparation containing CYP2C9 was found to be $1280 \pm 340$ nmol min $^{-1} \mathrm{mg}$ protein ${ }^{-1}$.

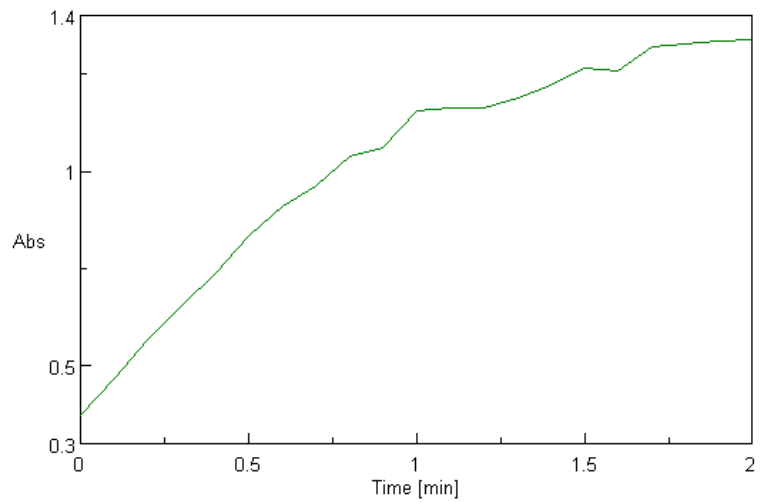

Figure 3. NADPH-cytochrome c reduction assay to measure the OxR content in the E. coli membrane protein preparation of CYP2C9. The activity of $\mathrm{OxR}$ was determined as the rate of reduction of cytochrome $\mathrm{c}$ at $550 \mathrm{~nm}$ wavelength per $\mathrm{mg}$ membrane protein. The $\mathrm{x}$ axis represents the time of incubation (minutes) while axis $y$ shows the absorbance of the reduced cytochrome c solution.

\section{Hydroxylase activities of CYP2C9 towards valsartan and tolbutamide. The} chromatograms obtained from incubation mixture containing the expressed CYP2C9 in comparison to that of the control cell (membrane fractions of control cell harbouring only pCWori+ plasmid) is shown in Figure 4. From the figure, valsartan and its metabolite (OH-valsartan) were eluted at retention times of 8.1 and $2.7 \mathrm{~min}$, respectively. The valsartan and $\mathrm{OH}$-valsartan peaks were subsequently proven as injection of pure compounds onto the system yielded peaks with the same retention times. Having optimized the chromatographic and incubation conditions, the rate of formation of $\mathrm{OH}$-valsartan from valsartan in the incubation mixture containing CYP2C9 was plotted against the substrate concentration to create a saturation plot (Figure 5). Saturation plot is used to determine the Michaelis-Menten kinetics of an enzyme, including the maximum rate of reaction $\left(\mathrm{V}_{\max }\right)$ when the enzyme is saturated with substrate, and the Michaelis constant $\left(\mathrm{K}_{\mathrm{m}}\right)$ that represents the concentration of substrate when the enzyme achieves half of its $\mathrm{V}_{\max }$ value.

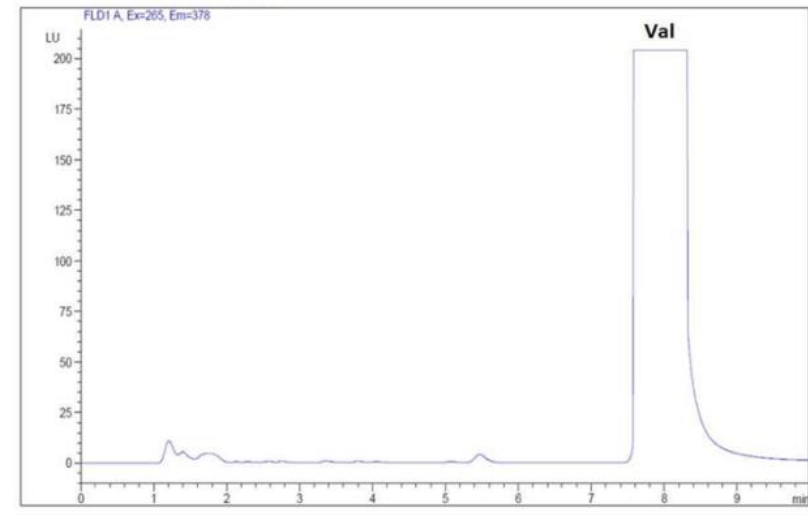

(a)

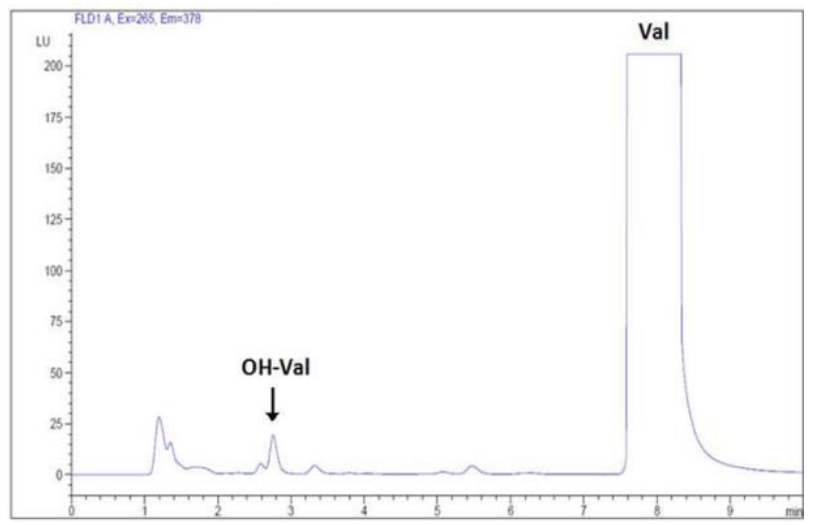

(b)

Figure 4. Representative HPLC chromatograms of incubations of valsartan $(150 \mu \mathrm{M})$ with 0.1 $\mathrm{mg} / 200 \mu \mathrm{l}$ control cell membranes (top) and 0.1 $\mathrm{mg} / 200 \mu \mathrm{l}$ of bacterial membranes expressing CYP2C9 and OxR (bottom) at $37^{\circ} \mathrm{C}$ for $45 \mathrm{~min}$. The $\mathrm{x}$ axis shows the retention time (minutes) whereas axis $y$ represents the fluorescence absorbance of the analytes (in I.U.). Peak labelled as $\mathrm{Val}$ (valsartan) was eluted at retention time of $8.1 \mathrm{~min}$. OH-valsartan (OH-Val) was observed as the peak with retention time of $2.7 \mathrm{~min}$. 


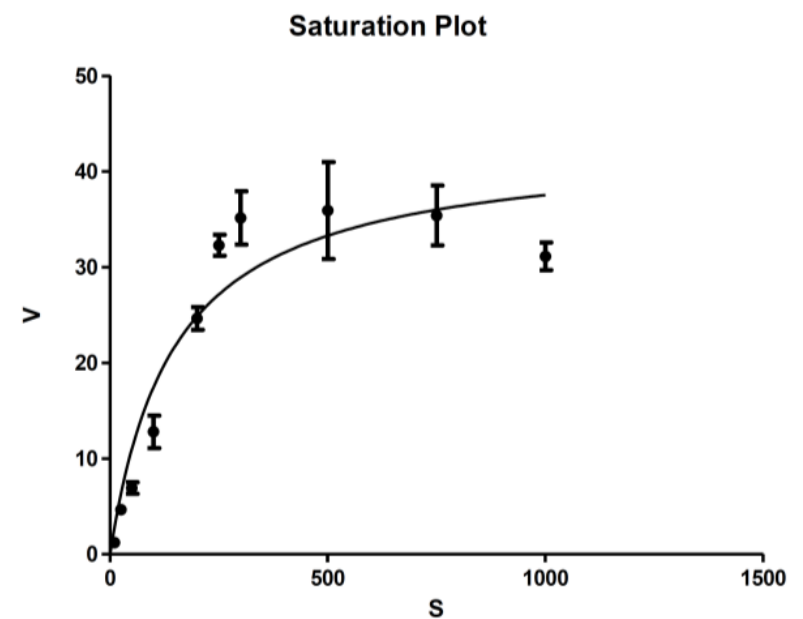

Figure 5. Saturation plot for valsartan 4hydroxylation in $\mathrm{DH} 5 \alpha$ membranes expressing the CYP2C9. Saturation plot was generated by plotting velocity against substrate concentrations. $\mathrm{V}=$ velocity (pmol min $\mathrm{m}^{-1} \mathrm{mg}$ protein ${ }^{-1}$ CYP2C9; $\mathrm{S}$ $=$ valsartan concentration $(\mu \mathrm{M})$.

These parameters can be used to determine the activity of the enzyme of interest, in this study, the expressed recombinant CYP2C9. From the saturation plot, $\mathrm{OH}$-valsartan formation demonstrated a typical hyperbolic curve with $\mathrm{K}_{\mathrm{m}}$ value of $146.0 \pm 53.6 \mu \mathrm{M}$ and $V_{\max }$ value of 43.0 $\pm 4.9 \mathrm{pmol} \mathrm{min}^{-1} \mathrm{mg}$ protein ${ }^{-1}$, determined by EZFit (Perrella Scientific, USA). Each data was generated from triplicate measurements. Because of the slight decrease in velocity of metabolite formation at high substrate concentration (1000 $\mu \mathrm{M})$ that might indicate substrate-inhibition, the data were reanalysed using GraphPad Prism (GraphPad Software Inc, USA) and the result showed a preference for Michaelis-Menten kinetics as compared to substrate-inhibition (data not shown). Kinetic of tolbutamide 4hydroxylation was also characterized with the expressed CYP2C9. Tolbutamide is accepted widely as a prototypic substrate for the assessment of hepatic CYP2C9 activity, both in vitro and in vivo. As with the case of valsartan, hydroxytolbutamide formation by CYP2C9 showed Michaelis-Menten kinetics with an apparent $K_{m}$ and $V_{\max }$ values of $273.0 \pm 62.9 \mu \mathrm{M}$

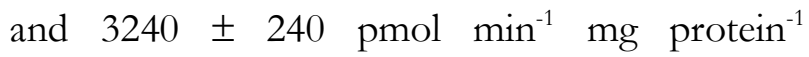
respectively (data not shown).

\section{DISCUSSION}

Impelled by the advent of recombinant DNA technology, many in vitro studies of human drug metabolism using heterologous expression systems in different host cells have been materialized. Among the many heterologous expression systems available, bacterial expression system is the most favourable in terms of high proliferation rate, high protein yield, low maintenance cost, and easy handling (Zelasko et al., 2013). E. coli is the most extensively utilized bacterial host in the production of recombinant human CYPs in attempt to generate ample amount of CYP proteins with relatively short culture periods for the study on drug metabolism and toxicology. While the advantages are clear, the drawback of this system is that the low expression of functional CYP of human origin due to their hydrophobicity, their requirements for heme incorporation and folding problems. After years of research to improve the functional expression of human CYP in E. coli, several strategies have been exploited to overcome this problem, including: (i) replacing the second codon at the Nterminal of native CYP sequence with GCT coding for Alanine; (ii) reduction of free energy for secondary structure formation by changing G:C pairs to A:T pairs in the first 10 codons; (iii) removal of hydrophobic segments at the $\mathrm{N}$ terminal; (iv) alignment to insert the sequence MALLLAVFL at the N-terminal; (v) coexpression of CYP and OxR; and (vi) incorporation of $\delta$-ALA as precursor for heme in culture media (Yun et al., 2006; Schroer et al., 2010; Zelasko et al., 2013).

Human CYPs are about 500 amino acid residues in length, including an $\mathrm{N}$-terminal endoplasmic reticulum (ER) retention signal. Removal of this $\mathrm{N}$-terminal ER retention signal and aligning an inserted $\mathrm{N}$-terminal membrane anchor (MALLLAVFL...) have been shown to markedly increase expression of CYP in bacterial cell without altering catalytic activity (Yun et al., 2006). Our laboratory has previously generated CYP cDNAs with N-terminal modifications to overcome the low expression level of human protein expression in E. coli (Pan et al., 2011; Tiong et al., 2010). These CYPs were successfully cloned into $\mathrm{pCWori}+$ expression vector and transformed 
into E. coli $\mathrm{DH} 5 \alpha$ cells. Table 1 lists the Nterminal modifications of the CYP2C9 cDNA that was used in this study. The $\mathrm{N}$-terminal modification involved replacing the second codon with GCT (substitution of ASP for ALA), deleting codons 3-20, and modifying codons 21-26 for bacterial codon bias. These modifications involved the strategies (i) and (iii) discussed above and have effectively removed the hydrophobic segment at the $\mathrm{N}$-terminal and the modified construct has resulted in successful expression of CYP2C9 in this study.

Co-expression of the CYPs and OxR has been found to increase catalysis activity in bacterial cells. To achieve this purpose, expression of both proteins was carried out independently using two independent expression plasmids for the proteins. This was accomplished by using pCWori+ (with CYP2C9 cDNA inserted) and pACYC (with OxR cDNA inserted) plasmids in our system. Both pCWorit and pACYC were two different but compatible plasmids suitable for use in bacterial expression system. pCWori+ possesses the ColE1 plasmid of origin, whereas $\mathrm{PACYC}$ carries the p15A origin of replication. These two replicons are commonly used control elements in bacterial cells to regulate and drive replication of plasmids and hence expression of any foreign genes inserted within. Furthermore, the two tandemly arranged tac promoter which are inducible by IPTG have facilitated the expression of CYP2C9. Besides, the presence of antibiotic resistance gene in pCWori+ vector (ampicillin resistance) and pACYC vector (chloramphenicol resistance) allow the selection and isolation of bacterial cell populations carrying both plasmids in culture media in which ampicillin and chloramphenicol have been incorporated. Figure 6 depicts the general maps of the constructed $\mathrm{pCW}-\mathrm{CYP}$ and pACYC-OxR plasmids adopted in this study.

Table 1. N-terminal modifications of CYP2C9 primary sequences adopted in this study.

\begin{tabular}{ccc}
\hline Protein & Sequence/construct & N-terminal amino acid sequence \\
\hline CYP2C9 & Native & MDSLVVLVLCLSCLLLLSLWRQSS \\
& Modified & MA...........................RSS \\
\hline
\end{tabular}
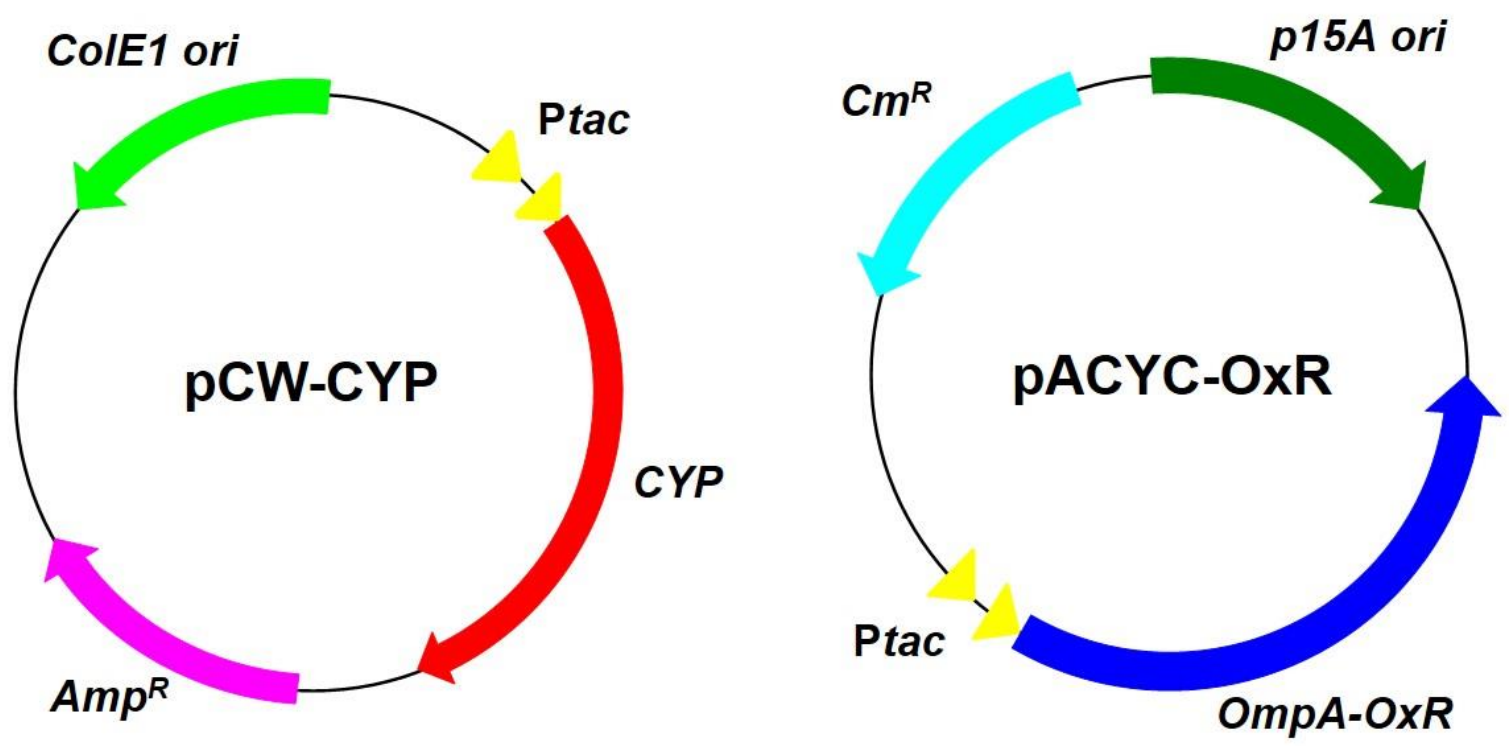

Figure 6. Map of the constructed pCW-CYP and pACYC-OxR with the insertion and the orientation of CYP gene and OxR gene. PCW-CYP contains ColE1 origin of replication (ColE1 or ), ampicillin resistance $\left(A m p^{R}\right)$ and two tandemly arranged tac promoter (Ptac), while pACYC-OxR harbours p15A origin of replication ( $p 15 A$ or $)$, chloramphenicol resistance $\left(\mathrm{Cm}^{\mathrm{R}}\right)$ and two Ptac. The OmpA bacterial leader sequence accounts for the first 21 amino acids at the $\mathrm{N}$-terminal of $O \times R(O m p A-O x R)$. 
Besides the construction of functional CYPs, the incubation conditions can also affect the level of expression of recombinant CYPs. Rich media such as Terrific broth was used as the incubation media for the E. coli culture to facilitate high-level protein expression. Since E. coli is unable to biosynthesize heme intracellularly, addition of the heme precursor $\delta$-ALA in the growth media can enhance the yield of spectrally active CYP, presumably owing to proper folding and incorporation of heme (Yun et al., 2006; Zelasko et al., 2013). A concentration of $0.5 \mathrm{mM}$ ALA is sufficient to enhance the expression of CYP in $E$. coli (Guengerich et al., 1996), but the concentration required for maximal expression varies among individual CYP and thus should be optimized. Incubation temperature is essential for successful expression of human CYPs in E. coli. Lower temperature at incubation is assumed to slow the expression of protein sufficiently to allow time for proper folding and heme incorporation. The optimal expression temperature tends to be between 26 and $32^{\circ} \mathrm{C}$ (Yun et al., 2006). The incubation time to carry out protein expression was set at $30^{\circ} \mathrm{C}$ as this was the temperature commonly used to express the recombinant CYPs. Besides temperature, the induction time should be optimized for each CYP. Typical induction time is 24-72 hours (Yun et al., 2006), and thus the induction time in this study has been set to 24 hours. Since E. coli is aerobic organism, the aeration of cultures may affect the expression of protein. Routine incubation was carried out at $200 \mathrm{rpm}$ on a shaking incubator and the total volume of culture media was capped at one-third of the flask volume to provide sufficient level of aeration for the bacterial growth.

Having isolated the membrane fractions from the bacterial cultures, the expression of the recombinant CYP2C9 was confirmed by Western blotting (Figure 1), indicated by detection of visible band around $56 \mathrm{kDa}$. Immunoblotting however can detect the expression of both apoprotein (CYP2C) protein without heme prosthetic group) and holoprotein (CYP2C) protein with heme prosthetic group), but not specifically the expression level of functional holoprotein. Therefore quantitative analysis using reduced-CO difference spectrophotometry was performed to measure the content of stoichiometrically active CYP per unit protein in the recombinant CYP2C9 preparations.

The expressed CYP2C9 protein was characterized for its absorbance through reducedCO difference spectra. This spectral characterization has been used as a classical assay to examine CYP expression and activity since the discovery of the enzyme in early 1960s (Omura and Sato, 1964; Guengerich et al., 2009). As illustrated in Figure 2, CYP2C9 expressed in this study exhibited the characteristic absorbance peak around $450 \mathrm{~nm}$ and thus the expression of the holoenzyme was confirmed. A relatively small absorbance peak was observed around $420 \mathrm{~nm}$ and this is due to low level of inactive CYP protein in the preparation. It is customary to observe a minor peak at $420 \mathrm{~nm}$ in cDNAexpressed CYP preparations that represents the denatured form of the protein where there is no efficient folding in the protein tertiary structure and is likely due to the loss of cysteine thiolate linkage to the heme iron, causing instability of the ferrous/CO-bound form of the enzyme. Normally in the properly expressed CYPs, the P420 peak is rather small and does not affect the overall functionality of the CYPs (Narimatsu et al., 2004; Zheng et al., 2003). The total CYP content in membrane fractions containing CYP2C9 was found to be the high $(366.0 \pm 16.8)$, and was close to the reported values (in the range of $120-800$ pmol $\mathrm{mg}$ protein ${ }^{-1}$ ) of different CYP isoforms using the similar heterologous expression system (Blake et al., 1996; Boye et al., 2004, Pritchard et al., 2006).

Co-expression of OxR in CYP2C9 culture was also confirmed through Western blot, revealing a band around $75 \mathrm{kDa}$, corresponding to the reported molecular weight of OxR (Figure 1). Once again, immunoblotting could not conclude the expression level of functional $\mathrm{OxR}$ and thus spectral characterization was carried out to quantitate the amount of active OxR. The activity and level of expression of the co-expressed OxR was determined by NADPH cytochrome c reductase assay. The reduction of cytochrome $\mathrm{c}$ formed distinct bands in the absorption spectrum. The increase in absorbance at $550 \mathrm{~nm}$ was measured with time (Figure 3 ) and the activity of OxR was calculated using Equation 2. The membrane fractions showed cytochrome c reduction activity of $1280 \pm 340 \mathrm{nmol} \mathrm{min}{ }^{-1} \mathrm{mg}$ 
protein $^{-1}$ which was in line with the reported values ranging from 300 to $1300 \mathrm{nmol} \mathrm{min}{ }^{-1} \mathrm{mg}$ protein $^{-1}$ (Blake et al., 1996, Pritchard et al., 1998, Pritchard et al., 2006) and thus confirmed the expression of functional OxR in the recombinant cultures.

Valsartan is an orally active specific angiotensin II receptor antagonist which causes reduction in blood pressure and is used in treatment of hypertension (Flesch et al., 1997). It was first developed by Novartis and sold under the brand name DIOVAN which was the world's number-one selling high blood pressure medication (Siddiqui et al., 2011). Since valsartan is metabolised predominantly by CYP2C9 to form 4-hydroxyvaleryl metabolite, a HPLC-based assay to assess CYP2C9 activity in vitro using valsartan as the activity marker has been established in this study. Furthermore, this CYP2C9 substrate is relatively new as compared to the other wellestablished substrate probes for CYP2C9 such as diclofenac and (S)-flurbiprofen.

Both the substrate and metabolite were wellseparated by chromatography and distinguishable as individual peaks (Figure 4) in the assay developed in this study. Kinetic characterization of CYP2C9 was subsequently carried out by constructing the saturation plot (Figure 5) where valsartan concentration was plotted against the rate of formation of its metabolite $(\mathrm{OH}-$ valsartan). Metabolite formation demonstrated a hyperbolic curve in substrate concentrationvelocity plot, indicating increasing reaction rate at low substrate concentrations and saturating rate at higher concentrations. This hyperbolic curve in saturation plot revealed an enzyme-catalyzed reaction involving a single substrate and that the metabolite formation was in accordance to the Michaelis-Menten kinetics, with apparent $\mathrm{K}_{\mathrm{m}}$ value of $146.0 \pm 53.6 \mu \mathrm{M}$ and $V_{\max }$ value of 43.0 $\pm 4.9 \mathrm{pmol} \mathrm{min}^{-1} \mathrm{mg}^{-1}$ as determined in triplicates. The maximum velocity of the CYP2C9 prepared in this study compares favourably with those reported $V_{\max }$ values in literature $(27.2-216.9$ pmol min $^{-1} \mathrm{mg}$ protein ${ }^{-1}$ ), implying that the CYP2C9 preparation in this study was enzymatically as active as those prepared in other laboratories (Nakashima et al., 2005). On the other side, the CYP2C9 in this study exhibited a higher $\mathrm{K}_{\mathrm{m}}$ as compared to the reported $\mathrm{K}_{\mathrm{m}}$ values (41.9 $-55.8 \mu \mathrm{M})$ (Nakashima et al., 2005). The deviation of $\mathrm{K}_{\mathrm{m}}$ here was however relatively small with difference of less than one order of magnitude from the reported values, and coupled with acceptable $V_{\max }$ value, the assay can be accepted as a valid activity marker for CYP2C9. Kinetic parameters $\mathrm{K}_{\mathrm{m}}$ and $\mathrm{V}_{\max }$ were also determined in the present study with the second substrate probe, tolbutamide, with values of $273.0 \pm 62.9 \mu \mathrm{M}$ and $3240 \pm 240 \mathrm{pmol} \mathrm{min}^{-1} \mathrm{mg}$ protein ${ }^{-1}$ respectively. These values fell within the published range in literature, where $K_{m}$ and $V_{\max }$ values of 80.7-348.0 $\mu \mathrm{M}$ and 115.0-9130.0 pmol $\mathrm{min}^{-1} \mathrm{mg}$ protein ${ }^{-1}$ have been reported (Miners et al., 1988; Doecke et al., 1991; Veronese et al., 1993; Hickman et al., 1998; Shin et al., 1999; Komatsu et al., 2000). The difference among the $K_{m}$ values and the wide range of $V_{\max }$ values reported in literature might be caused by the use of different source of CYP2C9, in which the source of enzyme in the current study was membrane fractional preparation containing recombinant CYP2C9 and in the reference studies cited, human liver microsomes and recombinant CYP2C9 expressed in different cell lines such as E. coli, COS, and lymphoblastoid cells were the sources. Some investigators have suggested that the causes of the difference in Michaelis-Menten kinetic parameters could be due to: (a) inter-individual variation from using liver microsomes isolated from donors with different genetic/disease/drug backgrounds, (b) different heterologous expression system in the case of recombinant CYPs, owing to the unique physiological conditions in each system that affect the CYP quantity/affinity/activity profiles, and (c) interlaboratory variations including difference in experimental conditions (Ong et al., 2013). These variations and their causes have important implications on the validity of metabolic in vitro-in vivo quantitative extrapolations and thus these variations should be taken into consideration when conducting such extrapolations. Considering all the facts above, both $\mathrm{K}_{\mathrm{m}}$ and $\mathrm{V}_{\max }$ values from this study reside close to and within the variability of reported values for CYP2C9 in the literatures, the assays (using valsartan and tolbutamide) can therefore be accepted as valid activity markers for CYP2C9. 


\section{CONCLUSION}

In this study, CYP2C9 was successfully expressed in bacterial cells as indicated by the immunoblotting, reduced $\mathrm{CO}$ difference spectroscopy and HPLC-based assays. The kinetic data of the expressed CYP2C9 were close to the published values indicating that the protein expressed in the membranes of $E$. coli was catalytically active and fully functional. The established assays will serve as an investigational tool in drug metabolism and drug interaction studies involving this functionally important CYP isoform.

\section{ACKNOWLEDGEMENTS}

The work described in this paper is in part supported by the Monash University Seed Grant (no BCHH-SS-4-02-2010).

\section{REFERENCES}

Blake, J. A., Pritchard, M., Ding, S., Smith, G., Burchell, B., Wolf, C. R. and Friedberg, T. 1996. Coexpression of a human P450 (CYP3A4) and P450 reductase generates a highly functional monooxygenase system in Escherichia coli. FEBS Letters 397: 210-214.

Boye, S., Kerdpin, O., Elliot, D., Miners, J., Kelly, L., McKinnon, R., Bhasker, C., Yoovathaworn, K. and Birkett, D. 2004. Optimizing bacterial expression of catalytically active human cytochromes P450: comparison of CYP2C8 and CYP2C9. Xenobiotica 34: 49-60.

Bradford, M. M. 1976. A rapid and sensitive method for the quantitation of microgram quantities of protein utilizing the principle of protein-dye binding. Analytical Biochemistry 72: 248-254.

Doecke, C. J., Veronese, M. E., Pond, S. M., Miners, J.O., Birkett, D. J., Sansom, L. N. and McManus, M. E. 1991. Relationship between phenytoin and tolbutamide hydroxylations in human liver microsomes. British Journal of Clinical Pharmacology 31: 125-130.

Flesch, G., Muller, P. and Lloyd, P. 1997. Absolute bioavailability and pharmacokinetics of valsartan, an angiotensin II receptor antagonist, in man. European Journal of Clinical Pharmacology 52: 115-120.

Foti, R. S., Wienkers, L. C. and Wahlstrom, J. L. 2010. Application of cytochrome P450 drug interaction screening in drug discovery. Combinatorial Chemistry and High Throughput Screening 13: 145-158.

Gillam, E. M. J., Guo, Z. Y. and Guengerich, F. P. 1994. Expression of modified human cytochrome P450 2E1 in Escherichia coli, purification, and spectral and catalytic properties. Archives of Biochemistry and Biophysics 312: 59-66.
Guengerich, F. P., Martin, M. V., Guo, Z. and Chun, Y-J. 1996. Purification of functional recombinant P450s from bacteria. Methods in Ensymology 272: 35-44.

Guengerich, F. P., Martin, M. V., Sohl, C. D. and Cheng, Q. 2009. Measurement of cytochrome P450 and NADPHcytochrome P450 reductase. Nature Protocols 4: 1245-1251.

Hickman, D., Wang, J. P., Wang, Y. and Unadkat, J. D. 1998. Evaluation of the selectivity of in vitro probes and suitability of organic solvents for the measurement of human cytochrome P450 monooxygenase activities. Drug Metabolism and Disposition 26: 207-215.

Komatsu, K., Ito, K., Nakajima, Y., Kanamitsu, S. I., Imaoka, S., Funae, Y., Green, C. E., Tyson, C. A., Shimada, N. and Sugiyama, Y. 2000. Prediction of in vivo drug-drug interactions between tolbutamide and various sulfonamides in humans based on in vitro experiments. Drug Metabolism and Disposition 28: 475-481.

Miners, J. O., Smith, K. J., Robson, R. A., McManus, M. E., Veronese, M. E. and Birkett, D. J. 1988. Tolbutamide hydroxylation by human liver microsomes. Kinetic characterisation and relationship to other cytochrome P450 dependent xenobiotic oxidations. Biochemical Pharmacolology 37: 1137-1144.

Nakashima, A., Kawashita, H., Masuda, N., Saxer, C., Niina, M., Nagae, Y. and Iwasaki, K. 2005. Identification of cytochrome P450 forms involved in the 4-hydroxylation of valsartan, a potent and specific angiotensin II receptor antagonist, in human liver microsomes. Xenobiotica 35: 589602.

Narimatsu, S., Imoto, K., Isobe, T., Kiryu, K., Naito, S., HichiyaI, H., Funae, Y., Hanioka, N. and Yamamoto, S. 2004. The roles of amino acid residues at positions 43 and 45 in microsomal contents and enzymatic functions of rat CYP2D1 and CYP2D2. Biochemical and Biophysical Research Communications 324: 627-633.

Omura, T. and Sato, R. 1964. The carbon monoxide-binding pigment of liver microsomes. I. Evidence for its hemoprotein nature. Journal of Biological Chemistry 239: 2370 2378.

Ong, C. E., Pan, Y., Mak, J. W. and Ismail, R. 2013. In vitro approaches to investigate cytochrome P450 activities: update on current status and their applicability. Expert Opinion on Drug Metabolism and Toxicology 9:1097-1113.

Pan, Y., Abd-Rashid, B. A., Ismail, Z., Ismail, R., Mak, J. W. and Ong, C. E. 2011. Heterologous expression of human cytochromes P450 2D6 and 3A4 in Escherichia coli and their functional characterization. The Protein Journal 30: 581-591.

Pan, Y., Abd-Rashid, B. A., Ismail, Z., Ismail, R., Mak, J. W., Pook, P.C., Er, H.M. and Ong, C. E. 2010. In vitro modulatory effects on three major human cytochrome P450 enzymes by multiple active constituents and extracts of Centella asiatica. The Journal of Ethnopharmacology 130: 275-283.

Pan, Y., Tiong, K. H., Abd-Rashid, B. A., Ismail, Z., Ismail, R., Mak, J. W. and Ong, C. E. 2012 Inhibitory effects of cytochrome P450 enzymes CYP2C8, CYP2C9, CYP2C19 and CYP3A4 by Labisia pumila extracts. Journal of Ethnopharmacology 143: 586-591.

Pritchard, M. P., Glancey, M. J., Blake, J. A., Gilham, D. E., Burchell, B., Wolf, C. R. and Friedberg, T. 1998. Functional co-expression of CYP2D6 and human NADPH cytochrome $\mathrm{P} 450$ reductase in Escherichia coli. Pharmacogenetics and Genomics 8: 33-42.

Pritchard, M. P., McLaughlin, L. and Friedberg, T. 2006. Establishment of functional human cytochrome P450 monooxygenase systems in Escherichia coli. In Cytochrome P450 Protocols, ed. I. R. Phillips and E. A. Shepard, pp. 1928. New Jersey: Springer. 
Schroer, K., Kittelmann, M. and Lutz, S. 2010. Recombinant human cytochrome P450 monooxygenases for drug metabolite synthesis. Biotechnology and Bioengineering 106: 699706.

Shin, J. G., Soukhova, N. and Flockhart, D. A. 1999. Effect of antipsychotic drugs on human liver cytochrome P-450 (CYP) isoforms in vitro: preferential inhibition of CYP2D6. Drug Metabolism and Disposition 27: 1078-1084.

Siddqui, N., Husain, A., Chaudhry, L., Alam, M. S., Mitra, M. and Bhasin, P. S. 2011. Pharmacological and pharmaceutical profile of valsartan: a review. Journal of Applied Pharmacentical Science 1: 12-19.

Tiong, K. H., Yiap, B. C., Tan, E. L., Ismail, R. and Ong, C. E. 2010. Functional characterization of cytochrome P450 2A6 allelic variants CYP2A6*15, CYP2A6*16, CYP2A6*21, and CYP2A6*22. Drug Metabolism and Disposition 38: 745-751.

van Booven, D., Marsh, S., McLeod, H., Carrillo, M. W., Sangkuhl, K., Klain, T. E. and Altman, R. B. 2010. Cytochrome P450 2C9-CYP2C9. Pharmacogenetetics and Genomics 20: 277-281.

Vermilion, J. L. and Coon, M. J. 1978. Purified liver microsomal NADPH-cytochrome P450 reductase: spectral characterization of oxidation-reduction states. Journal of Biological Chemistry 253: 2694-2704.

Veronese, M. E., Doecke, C. J., Mackenzie, P. I., McManus, M. E., Miners, J. O., Rees, D. L., Gasser, R., Meyer, U. A. and Birkett, D. J. 1993. Site-directed mutation studies of human liver cytochrome P-450 isoenzymes in the CYP2C subfamily. The Biochemical Journal 289: 533-538.

Yun, C. H., Yim, S. K., Kim, D. H. and Ahn, T. 2006. Functional expression of human cytochrome P450 enzymes in Escherichia coli. Current Drug Metabolism 7: 411-429.

Zelasko, S., Palaria, A. and Das A. 2013. Optimizations to achieve high-level expression of cytochrome P450 proteins using Escherichia coli expression systems. Protein Expression and Purification 92: 77-87.

Zheng, Y-M., Henne, K. R., Charmley, P., Kim, R. B., McCarver, D. G., Cabacungan, E. T., Hines, R. N. and Rettie, A. E. 2003. Genotyping and site-directed mutagenesis of a cytochrome P450 meander Pro-X-Arg motif critical to CYP4B1 catalysis. Toxicology and Applied Pharmacology 186: 119-126. 